\title{
Prevalence of Hypertension in Semi-Urban area of Nepal
}

\author{
Koju $\mathrm{R}^{*}$, Manandhar $\mathrm{K}^{*}$, Gurung $\mathrm{R}^{*}$, Pant $\mathrm{P}^{*}$, Bedi TRS* \\ *Department of Internal Medicine, Dhulikhel Hospital - KUH
}

\begin{abstract}
Hypertension is one of the major cardiovascular problems in middle and low income countries. There are few studies conducted in Nepal which shows significant number of hypertensive population in suburban area. Systematic random sampling from voter lists of all the members more than 18 years of age of Dhulikhel Municipality was done. 796 among 1150 sampled population were interviewed and their blood pressure was measured twice using mercury sphygmomanometer in standard method in their home. The average blood pressure was taken for study. Hypertension was defined as systolic blood pressure $\geq 140 \mathrm{mmHg}$ and/or diastolic blood pressure $\geq 90$ $\mathrm{mmHg}$, and/or on antihypertensive treatment. Total number of study population was 796. Among them $490(61.6 \%)$ were female and $306(38.4 \%)$ were male with age ranging from 18 years to 88 years (mean $48.41 \pm 17.38$ ). Overall prevalence of hypertension was $28.9 \%$ (male $28.8 \%$, female $29 \%)$. The prevalence was increasing with age ( $11.1 \%$ in $<30$ years to $44.8 \%$ in $>70$ years). According to JNC 7, 29.1\% were in Pre-hypertensive group. This study shows that Hypertension is significant in suburban area of Nepal.
\end{abstract}

Key words: Hypertension, Blood Pressure, Prevalence, Nepal 


\section{INTRODUCTION}

Cardiovascular disease is a major health problem throughout the world and a common cause of premature morbidity and mortality. The recent trend shows that cardiovascular disease is also becoming a major problem in low and middle income countries. The more prevalent infectious diseases and malnutrition in developing countries are going to be replaced by non-communicable disease in the near future. By the year 2020, noncommunicable diseases are expected to account for 7 out of every 10 deaths in the developing regions, compared with less than half at present ${ }^{1}$. Hypertension, among cardiovascular disease is one of the major components of the non-communicable diseases.

Hypertension is an established major risk factor underlying the epidemic of coronary and cardiovascular diseases in most developed countries, and it has been shown to be a major public health problem in many developing countries since the $1970 s^{2}$. The rate of hypertension and its complications are decreasing in developed countries whereas it is increasing in developing countries $^{3,4,5,6}$. Although hypertensive illness is more prevalent in urban areas, it is also seen in people of rural areas with low socioeconomic condition 6,7 . Unfortunately the prevalence of hypertension is increasing worldwide but awareness, treatment and control rates are very poor ${ }^{8}$.

The objective of this study was to estimate the prevalence of hypertension according to the recent criteria for diagnosis and to determine the status of treatment and control of hypertension in suburban area - Dhulikhel municipality.

\section{METHODOLOGY}

This study was carried out in semi-urban area of Nepal - Dhulikhel in 2007. From the recent voters list obtained from municipality, total 1150 samples were selected by systemic random sampling. The sample populations were more than 18 years of age. Among 1150 sample size, 796 respondents were studied. Others were either out of home or unwilling to be participated. They were interviewed with structured questionnaire. Their blood pressure was measured using mercury sphygmomanometer with appropriate cuff size in standard method in their home. The blood pressure was measured two times on upper arm in sitting position in the interval of 30 minutes. The average blood pressure was taken for study. Hypertension was defined as systolic blood pressure $\geq$ $140 \mathrm{mmHg}$ and/or diastolic blood pressure $\geq 90$ $\mathrm{mmHg}$. Those who were diagnosed previously and taking antihypertensive medication were also defined as hypertensive. The diagnosis and classification of hypertension was done according to the JNC-7 report ${ }^{9}$. The data were analyzed using SPSS 11.5 software.

\section{RESULT}

Total number of study population was 796 . Among them $490(61.6 \%)$ were female and $306(38.4 \%)$ were male. The age ranged from 18 years to 88 years with mean $48.41 \pm 17.38$.

Overall prevalence of hypertension was $28.9 \%$ (male $28.8 \%$, female $29 \%$ ).

The prevalence was increasing with age. The prevalence among below 30 years of age was 19 out of $171(11.1 \%)$ whereas it was 43 out of 96 $(44.8 \%)$ in more than 70 years of age.

Table 1: Number of study sample and prevalence of hypertension.

$\begin{array}{lllc}\text { Sex } & \text { Number } & \text { Percentage } & \text { Prevalence of Hypertension } \\ \text { Male } & 306 & 38.4 & 28.8 \% \\ \text { Female } & 490 & 61.6 & 29.9 \% \\ \text { Total } & 796 & 100 & 28.9 \%\end{array}$


Figure 1: Figure showing prevalence of hypertension in different age groups.

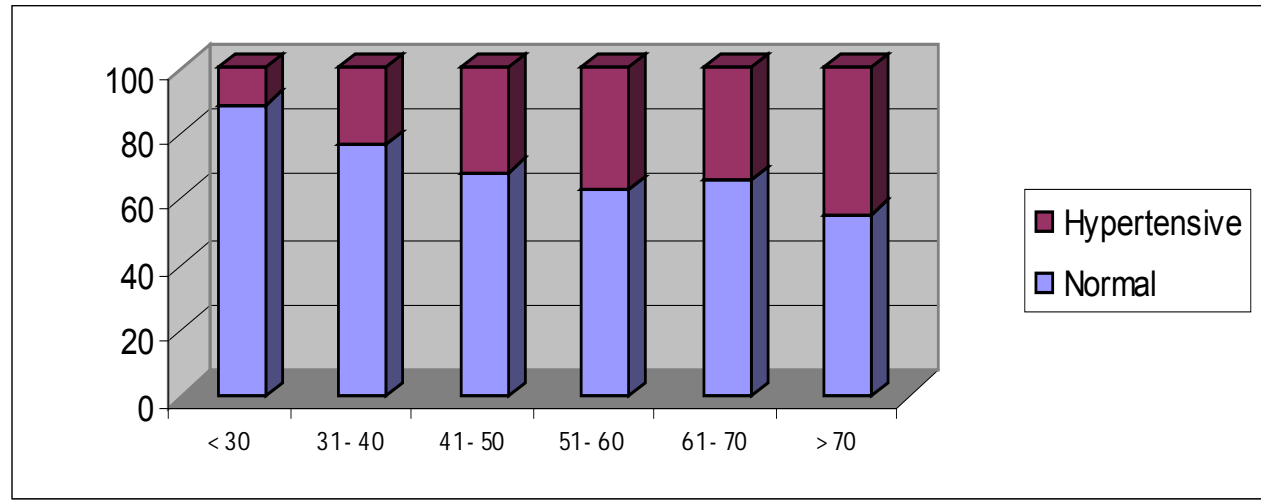

Figure 2: Pie chart showing classification blood pressure

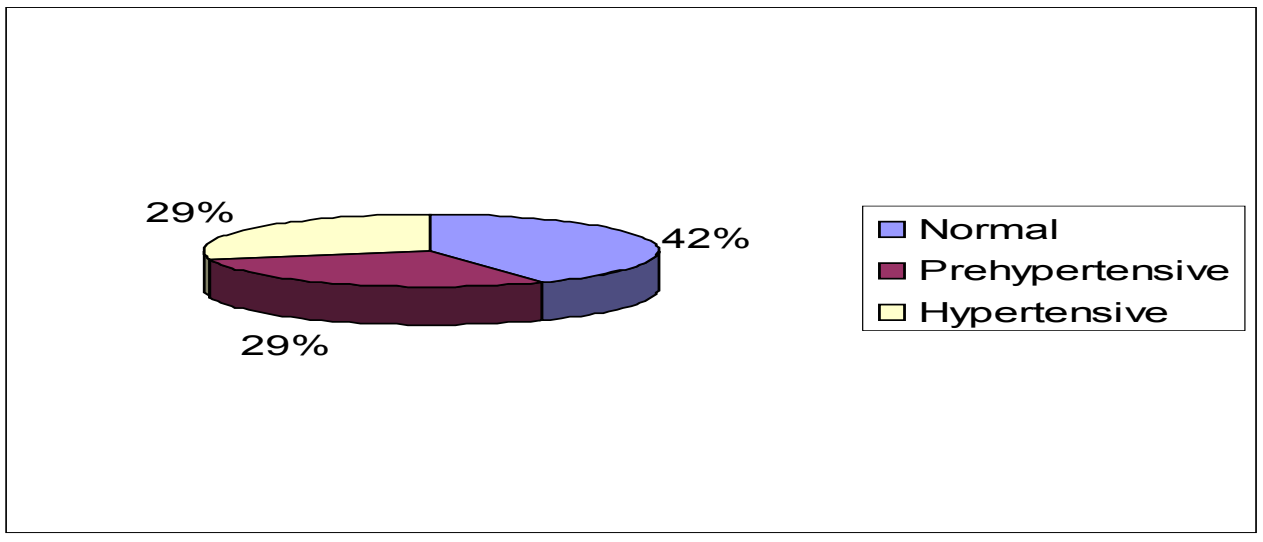

Among study population, $69.9 \%$ of hypertensive patients were unaware of their hypertension. Only $18.3 \%$ of all were taking antihypertensive medications.

\section{Table 2. Risk Factors among study population}

$\begin{array}{lll} & \text { Smoking } & \text { Diabetes } \\ \text { Normal } & 39.70 \% & 3.20 \% \\ \text { Hypertensive } & 38.20 \% & 7.10 \%\end{array}$

Rate of smoking was similar among hypertensive and non hypertensives. Diabetes was higher among hypertensive $(p<0.05)$

\section{DISCUSSION}

The overall prevalence of hypertension in this study was $28.9 \%$ (male, $28.8 \%$; female $30 \%$ ). In a study done by Pandey et al in 1981, the overall prevalence was $5.98 \%$ in rural population of $\mathrm{Ne}$ pal according to the $1978 \mathrm{WHO}$ criteria for the diagnosis of hypertension ( $\mathrm{BP} \geq 165 / 95 \mathrm{mmHg})^{10,11}$. The prevalence of hypertension was significantly increased in latest study done in suburban area of Nepal by Sharma et al. in 2006 according to JNC 7 which showed the prevalence was $19.7 \%$ $(22.2 \%$ in men and $17.3 \%$ in women, $\mathrm{P}<0.05)$ 12. Shrestha et el found the prevalence of $22.7 \%$ among urban population aged more than 40 years ${ }^{13}$. Similar trends were found worldwide.

In a meta-analysis, it has been found that prevalence of hypertension has increased by 30 times among urban population over a period of 55 years and about 10 times over a period of 36 years in India ${ }^{14}$.

Keamey et al analyzed worldwide hypertension prevalence data published from 1998 to 2002 which showed $26.4 \%(95 \% \mathrm{Cl} 26.0-26.8 \%)$ of the adult population in 2000 had hypertension ( $26.6 \%$ of men and $26.1 \%$ of women), and $29.2 \%$ were projected to have this condition by 2025 $(29.0 \% \text { of men and } 29.5 \% \text { of women })^{15}$. In this study the one third of population $232(29.1 \%)$ was Pre-hypertensive according to JNC 7. They have doubled the risk of developing hypertension in 
future.

The prevalence of hypertension in China in adult population of 35 to $74 \mathrm{yrs}$ was $27.2 \%$ in a recent study ${ }^{16}$. In a study done in Thiruvananthapuram city in Kerala, the overall prevalence in adult population of more than $40 \mathrm{yrs}$ was $54.5 \% 8$. In a study carried out in Pakistan, the prevalence of hypertension in urban and rural population was $22.7 \%$ and $18.1 \%$ respectively ${ }^{11}$. Walf Maier et al. showed the prevalence of hypertension in North America was $27.6 \%$ while it was $44.2 \%$ in Europe. The overall prevalence of hypertension in United States in 1999-2002 was $28.6 \%{ }^{17}$. In Canada Tu $\mathrm{K}$ et al found that the age- and sexadjusted prevalence increased from 153.1 per 1000 adults in 1995 to 244.8 per 1000 in 2005, which was a relative increase of $60.0 \%{ }^{18}$.

The reported prevalence of hypertension varied around the world, with the lowest prevalence in rural India (3.4\% in men and $6.8 \%$ in women) and the highest prevalence in Poland $68.9 \%$ in men and $72.5 \%$ in women $)^{19}$. in our study, the number of hypertension is increasing with the advancing age, however the hypertension is $19 \%$ among less than 30 years age group.

Regarding the awareness and treatment of hypertension in our study, only $31.1 \%$ of the hypertensive subjects were aware that they had hypertension. Only $18.3 \%$ of the hypertensive subjects were taking antihypertensive medication. Similar findings were found by other investigators as well. According to National Health survey of Pakistan, $70 \%$ of the hypertensive patients were unaware of the disease ${ }^{20}$. In the study carried out in Kerala, India only $39 \%$ of the hypertensive individuals were aware of their condition, only $29 \%$ were treated with anti-hypertensive drugs and only $30.6 \%$ of the treated subjects had adequate control of blood pressure ${ }^{8}$.

Although smoking is one of the major risk factor associated with hypertension, it was found to be similar among both hypertensive and non-hypertensive group. Diabetes was significantly higher among hypertensive subjects. Shrestha et al found that hypertension was less common with normal plasma glucose than in those with diabetes $(18.8 \% \text { vs. } 36.7 \%)^{13}$.

This study showed that the prevalence of hypertension is increasing trend in not only urban but also suburban area in Nepal. This trend is similar worldwide. With this increasing trend, the awareness is far less which warrants the poor control of blood pressure and more complications. The timely detection, lifestyle modification, treatment and prevention are all important to deal with the alarming situation of increased prevalence of hypertension.

\section{REFERENCES}

1. Breithardt G, Eckardt L. The Global Burden of Cardiovascular Diseases. XXIst Annual Congress of the European Society of Cardiology 1999

2. Fuentes $\mathrm{R}$ et al. Hypertension in developing economies: a review of population-based studies carried out from 1980 to 1998. J Hypertens 18(5):521-9: 2000

3. Singh RB et al. Hypertension and stroke in Asia: prevalence, control and strategies in developing countries for prevention. J Hum Hypertens 14(10-11):749-63: 2000
4. Seedat YK. Hypertension in developing nations in sub-Saharan Africa. J Hum Hypertens Oct-Nov;14(10-11):739-47: 2000

5. Lenfant C. Can we prevent cardiovascular diseases in low- and middle-income countries? Bull World Health Organ 79(10):980-2; discussion 983-7: 2001

6. Kumar $\mathrm{V}$ et al. Health status of the rural elderly. J Rural Health 17(4):328-31: 2001

7. Soylu A et al. Effect of socioeconomic status on the blood pressure in children living in 
a developing country. Pediatr Int 42(1):3742:2000

8. Zachariah MG et al. Prevalence, correlates, awareness, treatment and control of hypertension in a middle-aged urban population in Kerala. Indian Heart J. 2003; 55:245-251

9. Chobanian AV et al; National Heart, Lung, and Blood Institute Joint National Committee on Prevention, Detection, Evaluation, and Treatment of High Blood Pressure; National High Blood Pressure Education Program Coordinating Committee. The Seventh Report of the Joint National Committee on Prevention, Detection, Evaluation, and Treatment of High Blood Pressure: the JNC 7 report. JAMA. 2003;289(19):2560-72.

10. Pandey MR, Upadhyaya LR, Dhungel S, Pillaik K, Regmi HN, Neupane RP. Prevalence of Hypertension in a rural community in $\mathrm{Ne}$ pal. Indian Heart Journal. 1981 Nov-Dec. 33(6): 284-289.

11. Pandey MR. Hypertension in Nepal. Bibl Cardiol. 1987; 42:68-76.

12. Sharma et al. Study of Prevalence, Awareness and Control of Hypertension in a Suburban Area of Kathmandu, Nepal. Indian Heart Journal.2006; 58: 34-37

13. Shrestha UK, Singh DL, Bhattarai MD The prevalence of hypertension and diabetes defined by fasting and 2-h plasma glucose criteria in urban Nepal, Diabetic Medicine 2006, vol. 23, no10, pp. 1130-1135 [6 page(s) (article)] (22 ref.)

14. Gupta R. Meta-analysis of prevalence of Hypertension in India. Indian Heart J. 1997; 49:43-48.

15. Kearney PM; Whelton M; Reynolds K; Muntner P; Whelton PK; He J Global burden of hypertension: analysis of worldwide data. Lancet 2005 Jan 15;365(9455):217-23.

16. Gu D, Reynolds K, Wu X, Chen J, Duan X, Muntner $P$, et al; InterASIA Collaborative Group. The International Collaborative Study of Cardiovascular Disease in ASIA. Prevalence Awareness, treatment and control of hypertension in China. Hypertension 2002; 40:920.

17. Hajjar I, Kotchen JM Kotchen TA. Hypertension: trends in prevalence, incidence, and control. Annu Rev Public Health. 2006;27:465-90

18. Tu K, Chen Z, Lipscombe LL Prevalence and incidence of hypertension from 1995 to 2005: a population-based study CMAJ. 2008 May 20;178(11):1458-60.

19. Kearney, Patricia M; Whelton, Megan; Reynolds, Kristi; Whelton, Paul K; He, Jiang Worldwide prevalence of hypertension: a systematic review Journal of Hypertension January 2004 - Volume 22 - Issue 1 - pp 1119

20. Health profile of the people of Pakistan. Pakistan Medical Research Council. Islamabad network publication service 1998. 